\title{
The Emergence of Service Robots at Restaurants: Integrating Trust, Perceived Risk, and Satisfaction
}

\author{
Kyung Hwa Seo ${ }^{1}$ and Jee Hye Lee ${ }^{2, *(\mathbb{D}}$ \\ 1 Department of Hotel Culinary Arts and Bakery, Ulsan College, Ulsan 44022, Korea; khseo@uc.ac.kr \\ 2 Department of Food \& Nutrition, University of Ulsan, Ulsan 44610, Korea \\ * Correspondence: 1ljh2000@ulsan.ac.kr
}

Citation: Seo, K.H.; Lee, J.H. The Emergence of Service Robots at Restaurants: Integrating Trust, Perceived Risk, and Satisfaction. Sustainability 2021, 13, 4431. https://doi.org/10.3390/su13084431

Academic Editor: Brian Garrod

Received: 4 March 2021

Accepted: 10 April 2021

Published: 15 April 2021

Publisher's Note: MDPI stays neutral with regard to jurisdictional claims in published maps and institutional affiliations.

Copyright: (c) 2021 by the authors. Licensee MDPI, Basel, Switzerland. This article is an open access article distributed under the terms and conditions of the Creative Commons Attribution (CC BY) license (https:// creativecommons.org/licenses/by/ $4.0 /)$.

\begin{abstract}
As various types of robots increasingly influence consumers' service experiences, companies need to consider how to be competitive in this new artificial intelligence and service automation business environment. However, only limited studies have investigated the factors involved in consumer behaviors toward robot restaurant visitors and their impacts. This study integrates trust, the perceived risk, and satisfaction with the well-known Technology Acceptance Model's (TAM) original constructs (perceived usefulness, perceived ease of use, and acceptance) in the robot service restaurant setting. A scenario-based online survey was performed on 338 respondents. Structural equational modeling shows the direct impact of PU (perceived usefulness) and the indirect impact of PEOU (perceived ease of use) on consumers' revisit intention to robot restaurants. Trust significantly increases PU and PEOU toward a service robot, and increased trust in robot service decreases the perceived risk as well as increases satisfaction. Further, perceived risk decreases satisfaction and revisit intention. The study provides useful information for hospitality marketers to acknowledge how consumers accept robot service and better understand the key drivers of robot restaurant revisit intention.
\end{abstract}

Keywords: service robot; TAM; PU; PEOU; trust; perceived risk; satisfaction; revisit intention

\section{Introduction}

The emergence of robots in the service industry is one of the radical technical innovations of the current 4th Industrial Revolution. Service robots have been discussed in several studies, especially those in the services management setting. A service robot refers to the autonomous technology offered by a computer without human help and/or instructions [1]. In a front-line service setting, the term service robot refers to autonomous decision-making systems that enable interaction, communication, and delivery service to an organization's customers [2]. Professional and personal use of service robots is reported to be growing at $30 \%$ percent a year, and it is expected that the robotic market will reach USD 55.72 B in 2026 as the demand for service robots continues to increase [3].

Encountering hotels and restaurants where cooking and services are provided by robots is not just in the near future. It is an emerging reality. For example, in Japan, Hennna Hotel, an unmanned hotel, has been operating since 2015, managed only by robots for luggage-carrying, reception and communication, and cleaning [4]. The robot, Connie, at this Hilton hotel is responsible for concierge services, and Yobot, at Yotel stores, for a guest's bags [5]. A robot servant named A.L.O at the Aloft hotel, Cupertino, delivers items like shampoo, soap, towels, and bed linens to your room and also takes dirty laundry. These robots have also begun to appear at restaurants. Moley, a robotic kitchen chef with two robotic arms, cooks according to a given recipe and is available for sale [6]. Along the same line, Spyce, a restaurant with a robotic kitchen in Boston, prepares food in three minutes or less.

Further, it also appears that the COVID-19 pandemic has accelerated the avoidance of services with high levels of human contact. During the COVID-19 pandemic period, 
the interpersonal interactions associated with human employees could cause a greater risk of virus transmission. It is thus a logical argument that replacing human employees with a service robot could lower the risk of infection [7], especially in the hospitality industry with its high-contact services.

While some see the progress of robot technology as a challenge regarding jobs and unemployment, this implementation of robots enhances consumer service experiences and offers several positive benefits, such as improving service consistently, reducing waiting times, welcoming customers, or producing higher productivity that hospitality industries desire [8]. In particular, reduction of labor costs and increased efficiency are some of the major benefits that robots offer [9]. The unique particularity of the hotel and restaurant industry is its labor-intensive work environment [10]. Thus, the role of robots in the further integration of the consumer experience becomes crucial for sustainable business [11].

As various types of robots influence consumer service experiences, if companies are hesitant to adapt to the new artificial intelligence and service automation business environment, they may fall behind competitively in the market. This study raised the question of how consumers accept service robots and what variables mostly influence the behavioral intention of robot service restaurants. In light of this issue, a comprehensive model, using a solid theoretical basis and identifying the driving factors for behavioral intentions related to robot service can contribute to both academic study and industrial practice.

The Technology Acceptance Model (TAM) is the most well-known and widely applied theory used to explain the psychological mechanism for consumer acceptance of technology, such as mobile apps, bank information services, and e-commerce [12,13]. In TAM, perceived usefulness (PU) and perceived ease of use (PEOU) are critical elements that affect behavioral intention. Prior studies using TAM were widely applied to predict consumers' acceptance of information technology (IT) products, but it has been rarely applied to service robots [14]. Thus, an extended TAM model with new variables that explain service robot acceptance can offer better understanding of the potential consumer psychological mechanism behind their perception of robot restaurants.

This study pays attention to trust as a critical antecedent variable of TAM for service robot usage. The importance of trust in technology acceptance seems apparent since a large body of empirical research has validated that view [15-17]. According to several studies in the IT literature, trust lowers uncertainty that may arise from the online environment where it is likely to be out of one's control [18]. It is reasonable to argue that trust lowers the uncertainty that may arise from a service robot that is operated by an automated program with minimal or no human involvement $[19,20]$. In particular, unlike other industries, restaurants provide food which is directly related to health and life of their consumers (i.e., food poisoning causes illness), so more research on the level of TAM trust at robot restaurants is a priority.

Despite the rapid growth in the use of service robots, certain concerns have arisen with such fast robot adoption [21]. For example, technical problems related to the hardware and software systems in robots or uncertainties occurring during the interaction between robots and humans can lead to service failures [22,23]. Both trust and the perceived risks are viewed as motivational constructs in consumer psychology, often influencing subsequent behavioral response. Since trust and even perceived risk are crucial constructs of the service robot context where uncertainty is indeed present, it is reasonable to insist that these variables are well integrated in the new extended TAM model. This empirical evidence can have considerable practical value when guiding strategic initiatives undertaken by hospitality operators. Additionally, satisfaction is well established in the restaurant marketing literature as a critical variable of usage, intentions, and trust, and these and the perceived risk are critical antecedent variables of eventual and ongoing satisfaction [24-26].

Given the growth of robots in the industry, hospitality studies are interested in the following related topics: Perception, attitudes, and preferences regarding the use of robotics at restaurants and hotels $[21,27,28]$, the interaction between service robots and humans [29-31]; and the application of TAM and the perception of restaurant service robots 
among general managers [12]; the antecedents of customers' willingness to use AI robotic devices [32], and the service failure of robots [33,34]. Some of the existing robot research includes review papers and proposal papers that contains suggestions/directions for the hospitality industry [2,19,31,35-38]. However, it provides little guidance for practical decision management. That issue may be because of the relatively small number of companies that actually have adopted and are operating service robots in their hospitality industries. Determining the drivers of consumer behavioral intention toward robot restaurants at business hotels and further empirical verification of trust, perceived risk, and satisfaction as critical antecedent variables is now required since there is a lack of research on these issues.

To contribute to this emerging but still underdeveloped field of service robot research, we propose a research framework that can lead to a better understanding of potential consumers' psychological mechanism in the TAM model as applied to the robot service restaurant setting. The primary research issues thus are:

- Investigating the drivers of customers' behavioral intention of having robot restaurants at business hotels;

- Determining how to integrate TAM with trust, perceived risk, and satisfaction to predict consumer behavior in the context of robot service restaurants.

\section{Theoretical Background and Hypothesis Development}

\subsection{The Technology Acceptance Model (TAM)}

With the growing development of new technology, a decision regarding either technology acceptance or rejection is an important factor for the successful implementation and utilization of technology. In addition, during the last few decades, researchers have developed several models to explore why people decide to either accept or reject a technology and to determine what the antecedent variables are of such technology acceptance. This current study discusses the technology acceptance model suggested by Davis $[39,40]$. TAM is one of the most widely recognized and established models to explain technology acceptance [41-43]. TAM adapted Ajzen and Fishbein's theory [44] of reasoned action, representing the view that beliefs affect attitudes, which in turn result in intentions and behaviors. TAM originated based on that relationship of 'belief-attitude-intention-behavior' to explain user acceptance of technology [14]. Davis's theory [39] identified the two primary factors that motivate user technology adoption, namely, perceived usefulness (PU) and perceived ease of use (PEOU). PU and PEOU influence the attitudes and intention to use a technology, which in turn influences actual usage, the dependent variable of TAM [45]. Davis [40] defined PU as a person's subjective belief that an individual's job performance can be enhanced by using a particular technology [14,40]. PEOU is defined as an individual's belief that operating a particular system is easy and needs less effort $[14,40]$. Davis [40] insisted that user belief that a new technology is difficult to use means that this user will tend to reject its use even when the technology offers increased usefulness.

Initially, TAM was developed for employee technology acceptance in work-related activities, which was applicable to organizational settings. As TAM took a leading role in explaining users' acceptance of new technology, it was extended and modified into a variety of non-organizational sections [13]. A new extended and modified model that accounts for new external variables has been presented to explain the acceptance of new technology $[14,46]$. In this extended TAM, external factors, such as personal features (e.g., self-efficacy, risk, trust, and innovativeness) [47], system features (e.g., screen design) [48], and organizational features (e.g., training) [49] have been investigated, and their influences on attitude and behavior through the application of PU and PEOU have been determined.

These two crucial TAM constructs, PU and PEOU, have been studied in hospitality contexts to examine the acceptance of many technologies, such as hotel front office systems [42], Facebook commerce [50,51], user-generated content-adoption [52], radio frequency identification of cashless payment systems [13], self-service hotel technologies [53], mobile tourism applications [51], hotel tablet applications [54], disruptive mobile wallets [43], and biometric technologies at music festivals [45]. 
Although TAM has been investigated frequently for technology acceptance in the hospitality and tourism industry [46], limited research has been accomplished thus far on its application to restaurant robot service [14]. Most studies on technology acceptance have determined that perceived PEOU directly affects PU and intention to use and actual use [14,52,55-58]. Wang et al. [59] provided empirical evidence of the positive impact of perceived easiness of ride-sharing online service use on their perceived usefulness of ride-sharing online services. In a study conducted by Assaker [52] applying TAM on travel usage intention of online reviews, the results showed that PEOU and PU have a constant and direct effect on intentions. Thus, based on this literature, we assume that consumers' positive perception of usefulness and easiness of robot use will promote the revisiting intention to a robot restaurant, and the more consumers perceive a service robot as easy to use, the more they will perceive it as useful. Thus, the following hypotheses are offered:

Hypothesis 1. The PU of a robot service has a significantly positive impact on behavioral intention.

Hypothesis 2. The PEOU of a robot service has a significantly positive impact on behavioral intention.

Hypothesis 3. The PEOU of a robot service has a significantly positive impact on the PU of that robot service.

\subsection{Integrating Trust with the Technology Acceptance Model (TAM)}

In a broad sense, trust is defined as the belief that other people will behave within a predictable range [60]. According to Luhmann [60], trust can reduce consumers' perceived social complexity in the social environment in which they live and interact with e-venders. Trust lowers uncertain and unpredictable e-vendor behaviors, such as unfair pricing, unauthorized use of credit cards, exposure of privacy [61]. It is similar to the Internet based e-commerce literature where trust has been considered as one of the main reasons for consumers to refrain from engaging in e-commerce [62]. Tussyadiah et al. [19] stated that "trust is defined as a user's expectation that information technology artifacts, such as robots, and their likes will fulfill the expected responsibilities" (page 5). Because robots are programmed to perform various tasks and make decisions autonomously without human involvement, consumers should consider the risk of responsibility derived from that robot's performance $[19,20]$.

Thus, it is reasonable to argue that trust is an important element in robot service because of the high level of uncertainty that exists in most robot services. Especially, in hospitality settings, service encounters between humans frequently occur, so the replacement of robots for humans (employees) can result in great changes in the nature of the customer service experience and attitude, and behavioral outcomes [19,63,64]. Although trust in the e-commerce context has been an issue of extensive study, it is relatively novel in the case of robots in restaurant areas [11]. This current study highlights the need to understand how trust drives intention to use service robot restaurants in particular, and assumes that trust plays an important role in choosing robot service at a restaurant.

In the e-commerce context, trust allows consumers to be certain to receive the expected useful interaction whereas being 'not worthy of trust' makes consumers take a loss from the e-commerce transaction [16,17]. Previous studies have insisted that trust positively influences perceived ease of use by reducing the need for consumers to understand, monitor, and control the transaction circumstance; however, lack of trust forces consumers to have to pay special attention to the transaction process, thereby taking more time and effort [16,17]. This argument is consistent with that of Lee et al. [12], who argued that consumers who have high trust in service robot and expectation for their desired performance task will think that robots are useful and easy to use. Trust has also been determined to be a critical antecedent factor of the PU and PEOU of various technologies, such as mobile payments [65], information systems [66], online shopping [67], and e-commerce and e-government $[68,69]$. Based on this argument, the following hypotheses 
integrating trust with TAM variables have been developed. Further, based on the literature reviews, we assume that trust will increase the degree of PU and PEOU for the robot service at restaurants.

Hypothesis 4. Trust has a significantly positive impact on the PU of robot service.

Hypothesis 5. Trust significantly and positively impacts the PEOU of robot service.

\subsection{Trust, Perceived Risk, and Customer Satisfaction}

As trust in robot use plays an essential role in uncertain situations, the perceived risk toward robot use also plays an important role for robot acceptance. Even though the definition of risk has a multidimensional context [70], in the current study, perceived risk refers to consumers' perceptions of the uncertainty involved when the seriousness of undesirable consequences is a result of their behaviors [71-73]. Risk perception is also strongly associated with uncertainty and unfamiliarity [12]. In an e-commerce situation, consumers may experience a certain degree of risk because consumers' behaviors depend mostly on cyberspace objects (e.g., images or video clips) which cannot be touched smelled, or directly interacted with [18].

Consumers who face new technology may perceive a high level of psychological risks involving fear, hesitation, and even some negative feelings [74]. From this perspective, trust and the perceived risk are strongly interrelated in the robot context. Trust enhances the consumer's belief in technology, thereby attenuating the perceived risk in any new technology. Hence, trust reduces high levels of risk perception just as trust helps consumers attenuate uncertainty or anxiety about possible outcomes [75-77]. The opposite association between trust and the perceived risk has been examined in Internet technology [78,79]. Thus, the following hypotheses are offered:

Hypothesis 6. Trust has a significantly negative impact on perceived risk toward robot service restaurants.

Hypothesis 7. Trust has a significantly positive impact on customer satisfaction in a robot service restaurant.

According to Udo, Bagchi, and Kirs [80], perceived risk awakens negative emotions which in turn affect behavioral intentions. In technology-driven services, system failure increases perceived risk, such as personal risk, psychological risk, economic risk, privacy risk, and technical risk, which accompanies loss [80-83], and this multidimensional context of perceived risk can reduce satisfaction regarding e-service quality [83]. Additionally, numerous past studies in these various categories have shown the negative impact of risk on behavioral intention for an online shopping channel $[17,67,77,84,85]$; telemedicine services [41]; food purchases [86], and restaurant visits [87]. When individuals are uncomfortable with any uncertain and ambiguous situation, they tend to stay away from those situations [88]. Once consumers have experienced that robot service can produce negative consequences, these consumers' satisfaction will be decreased, and eventually they will avoid those negative outcomes by ceasing to revisit those restaurants. As noted above, there is agreement in the body of the literature that risk is related to satisfaction and intention to use robots. Unfortunately, there is limited research on the negative influence of robot usage/services.

This study also notices that satisfaction is a significant determinant of service robot usage due to satisfaction being an important driver that leads to a specific behavioral intention [80,85]. Ample literature has emphasized the importance of satisfaction, and companies put great effort into satisfying consumer's needs for success in competitive business. Trust and perceived risk are regarded as critical antecedents of satisfaction, which in turn, influences behavioral intentions. These relationships are well established in the restaurant marketing research [24-26]. Consumers' perceived risk decreases satisfaction, 
while trust increase satisfaction [89]. Thus, we suggest that trust lowers perceived risk and is the driving force behind customer satisfaction. This current study thus hypothesizes the association between perceived risk, satisfaction, and intention to revisit robot service restaurants as follow (Figure 1).

Hypothesis 8. Customer perceived risk has a significantly negative impact on satisfaction at robot service restaurants.

Hypothesis 9. Customer perceived risk has a significantly negative impact on behavioral intentions to visit a robot service restaurant.

Hypothesis 10. Customer satisfaction toward robot service restaurants has a significantly positive impact on behavioral intention.

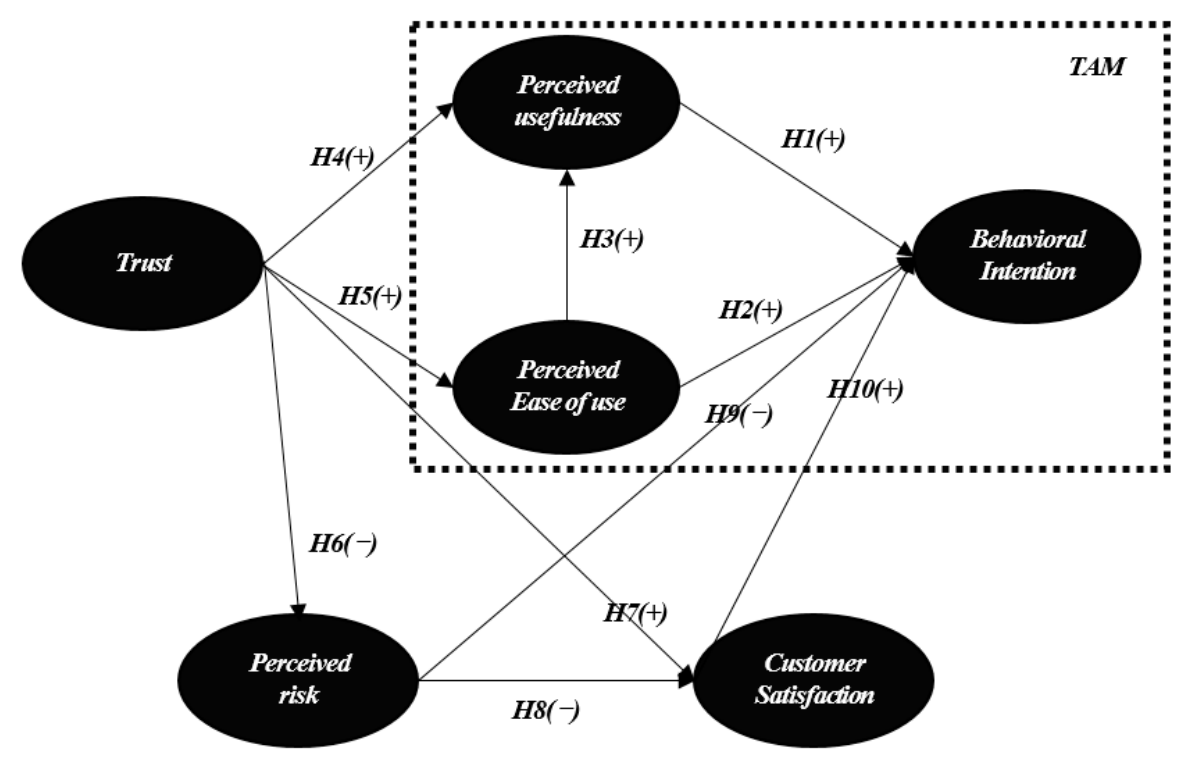

Figure 1. A proposed model.

\section{Methodology}

\subsection{Samples and Procedures}

Data collection were conducted utilizing a web-based survey platform. The target population for this study consisted of restaurant consumers in Korea. Using a professional online market research company, the questionnaire was distributed to research company panels who had visited a restaurant recently. These panels received online points which can be exchanged for cash as rewards. The questionnaire was designed to be scenario-based in order to provide a more realistic environment for the robot restaurants. Before the main data collection, a pilot test was conducted with 50 college students and 100 university students; the sample size of those who completed the questionnaire was regarded as sufficient to check reliability.

Two robot pictures (Figure 2) were shown to the participants due to the perception that participants will be affected by their previous exposure to robots from the mass media or other sources [90]. The following scenario was shown to the participants:

"You will stay overnight at the business hotel in Seoul, South Korea. You will visit the hotel's Italian restaurant for dinner and are going to eat tomato spaghetti. In this restaurant, you can order food and drinks through the artificial intelligence service robot or a digital menu board (tablet PC or mobile phone application, etc.). Ordered food is cooked by the shown robot according to the recipe and served by the shown robot. It is able to communicate with customers". 


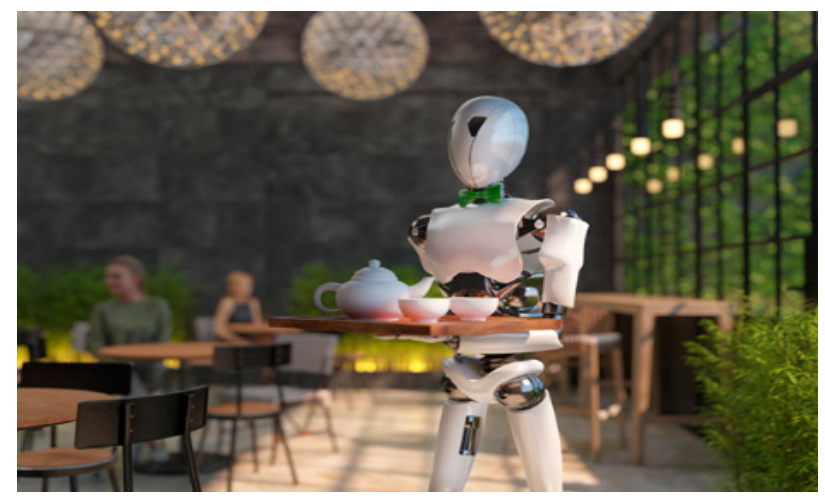

(left)

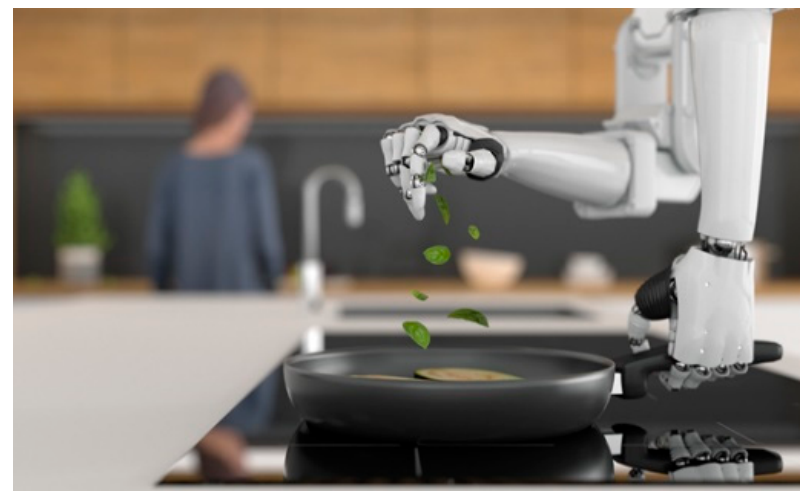

(right)

Figure 2. Photos (left) A serving robot; (right) A chef robot.

The participants also saw pictures of the service robots cooking and serving at a restaurant (Figure 2). A total of 364 panels submitted the questionnaires; from these, 26 questionnaires were removed for missing data and biased responses. Thus, the sample size used in this study (n) was 338 participants with a response rate of $92.9 \%$.

\subsection{Instrument Development}

Based on the previous literature, the concept of TAM for the hotel restaurant's artificial intelligence robot was applied, and it established the causal relationship between trust, the perceived risk, and customer satisfaction. First, the respondents answered all items using a 5-point scale (1: Strongly disagree to 5: Strongly agree) regarding PU, PEOU, trust, the perceived risk, customer satisfaction and behavioral intention. Second, questions were asked on the participants' demographics (e.g., gender, age, level of education, job, and region).

Measurement items for PU (3 items) and PEOU (three items) were adapted from Palau-Saumell [91], Herrero et al. [92], and Venkatesh et al. [93]. PU asked, "I find that robot services are useful in my daily life," and PEOU asked, "Using robot services is easy for me," and both included three items. Trust was composed of four items (e.g., "I believe that robot service is trustworthy") and adapted from Alalwan et al. [65] and Ejdys [94]. Perceived risk was composed of three measurement items (e.g., "Robots will have defects in technology and machines") and were adapted from Hansen et al. [79] and Mutahar et al. [95]. Customer satisfaction (two items) referred to the degree of the comprehensive psychological state, such as a favorable or unfavorable feeling about robotic service, and the measurement items (e.g., "Robots will provide services that satisfy my needs and preference") were adapted from Jin et al. [26], and Kim and Qu [96]. Behavioral intention had four measurement items (e.g., "I plan to visit a restaurant where robot service is provided") adapted from Kaushik et al. [53] and Jang and Lee [97].

\subsection{Data Analysis}

This study analyzed and verified the data using the Statistical Package for the Social Sciences (SPSS) and Analysis of Moment Structures (AMOS) program. All items were verified for validity and reliability using confirmatory factor analysis (CFA) in AMOS and Cronbach's alpha analysis in SPSS. The results for the proposed hypotheses and theoretical model are presented using the Structural Equation Model (SEM) in AMOS.

\section{Results}

\subsection{Profiles of the Study Participants}

The genders of the study participants were 165 (48.8\%) males and $173(51.2 \%)$ females. By age group 93 (27.5\%) were in their 20s, 96 (28.4\%) in their 30s, and 98 (29.0\%) in their 
40s and $51(15.1 \%)$ in their 50s. Most of the participants were confirmed to have graduated from a two-year college $292(86.4 \%)$.

\subsection{Study Reliability and Validity}

The standardized coefficients for all the items before the hypotheses were verified were 0.718 or higher, and Cronbach's alpha value was over 0.758 (see Table 1 ). The convergence validity and discriminant validity of the measurement scale were both verified using CFA analysis. Fornell and Larcker [98] provided the recommended cut-off of 0.70 for composite reliability. As a result, composite reliability was acceptable in the range of 0.788 and 0.928. Bagozzi and Yi [99] suggested that the cut-off score be 0.70 for the average variance extracted (AVE). The result ranged 0.621 to 0.831 , so that requirement was satisfied. The fit of the proposed items was generally confirmed as acceptable $\left(\chi^{2}=222.122 ; \mathrm{df}=137\right.$; $\chi^{2} / \mathrm{df}=1.621, \mathrm{GFI}=0.934 ; \mathrm{NFI}=0.944 ; \mathrm{CFI}=0.977 ; \mathrm{RMSEA}=0.043 ; \mathrm{RMR}=0.027$ ) The discriminant validity was explained by comparing each AVE value and the squared correlation value of two potential factors (see Table 2). The discriminant validity was explained by comparing the AVE value and the squared correlation value of two potential factors (see Table 2). The results were 0.010 to 0.466 , which was lower than the AVE value.

Table 1. Reliabilities and confirmatory factor analysis.

\begin{tabular}{|c|c|c|c|c|c|}
\hline Construct & $\begin{array}{l}\text { Standardized } \\
\text { Loadings }\end{array}$ & $t$-Value & $\begin{array}{l}\text { Composite } \\
\text { Reliabilities }\end{array}$ & AVE & $\begin{array}{c}\text { Cronbach's } \\
\text { Alpha }\end{array}$ \\
\hline \multicolumn{3}{|l|}{ Perceived usefulness } & 0.862 & 0.799 & 0.799 \\
\hline $\mathrm{PU}_{1}$ & 0.758 & Fixed & & & \\
\hline $\mathrm{PU}_{2}$ & 0.788 & $13.412^{* * *}$ & & & \\
\hline $\mathrm{PU}_{3}$ & 0.720 & $12.389^{* * *}$ & & & \\
\hline \multicolumn{3}{|l|}{ Perceived ease of use } & 0.903 & 0.695 & 0.868 \\
\hline $\mathrm{PEOU}_{1}$ & 0.827 & Fixed & & & \\
\hline $\mathrm{PEOU}_{2}$ & 0.894 & $18.095^{* * *}$ & & & \\
\hline $\mathrm{PEOU}_{3}$ & 0.776 & $15.731^{* * *}$ & & & \\
\hline \multicolumn{3}{|l|}{ Trust } & 0.928 & 0.831 & 0.890 \\
\hline $\mathrm{TR}_{1}$ & 0.828 & Fixed & & & \\
\hline $\mathrm{TR}_{2}$ & 0.838 & $17.950 * * *$ & & & \\
\hline $\mathrm{TR}_{3}$ & 0.853 & $18.395^{* * *}$ & & & \\
\hline $\mathrm{TR}_{4}$ & 0.775 & $16.108^{* * *}$ & & & \\
\hline \multicolumn{3}{|l|}{ Perceived risk } & 0.922 & 0.723 & 0.884 \\
\hline $\mathrm{PR}_{1}$ & 0.779 & Fixed & & & \\
\hline $\mathrm{PR}_{2}$ & 0.926 & $17.529 * * *$ & & & \\
\hline $\mathrm{PR}_{3}$ & 0.840 & $16.528^{* * *}$ & & & \\
\hline \multicolumn{3}{|l|}{ Customer satisfaction } & 0.788 & 0.621 & 0.758 \\
\hline $\mathrm{CS}_{1}$ & 0.852 & Fixed & & & \\
\hline $\mathrm{CS}_{2}$ & 0.718 & $8.356^{* * *}$ & & & \\
\hline \multicolumn{3}{|l|}{ Behavioral intention } & 0.923 & 0.691 & 0.898 \\
\hline $\mathrm{BI}_{1}$ & 0.835 & Fixed & & & \\
\hline $\mathrm{BI}_{2}$ & 0.866 & $19.079 * * *$ & & & \\
\hline $\mathrm{BI}_{3}$ & 0.838 & $18.216^{* * *}$ & & & \\
\hline $\mathrm{BI}_{4}$ & 0.783 & $16.545^{* * *}$ & & & \\
\hline
\end{tabular}

Note: Perceived usefulness (PU), perceived ease of use (PEOU), trust (TR), perceived risk (PR), customer satisfaction (CS), behavioral intention (BI). $\chi^{2}=222.122, \mathrm{df}=137, \chi^{2} / \mathrm{df}=1.621$, Goodness of Fit Index (GFI) = 0.934, Normed Fit Index $(\mathrm{NFI})=0.944$, Comparative Fit Index $(\mathrm{CFI})=0.977$, Root Mean Square Error of Approximation $($ RMSEA $)=0.043$; Root Mean Square Residual $($ RMR $)=0.027{ }^{* * *} p<0.001$. 
Table 2. Correlations Estimates.

\begin{tabular}{cccccccc}
\hline & $\mathbf{1}$ & $\mathbf{2}$ & $\mathbf{3}$ & $\mathbf{4}$ & $\mathbf{5}$ & $\mathbf{6}$ & $\mathbf{M} \pm$ S.D. \\
\hline 1. PU & $0.799^{\mathrm{a}}$ & $0.460^{\mathrm{b}}$ & 0.466 & 0.010 & 0.023 & 0.323 & $3.877 \pm 0.675^{\mathrm{c}}$ \\
2. PEOU & & 0.695 & 0.257 & 0.011 & 0.017 & 0.194 & $3.729 \pm 0.761$ \\
3. TR & & & 0.831 & 0.030 & 0.075 & 0.462 & $3.330 \pm 0.699$ \\
4. PR & & & & 0.723 & 0.238 & 0.026 & $3.718 \pm 0.731$ \\
5. CS & & & & & 0.621 & 0.086 & $2.85 \pm 0.832$ \\
6. BI & & & & & & 0.691 & $3.29 \pm 0.752$ \\
\hline
\end{tabular}

Perceived usefulness (PU), perceived ease of use (PEOU), trust (TR), perceived risk (PR), customer satisfaction (CS), behavioral intention (BI). ${ }^{a}$ Average variance extracted (AVE). ${ }^{b}$ Matrix entries are the square correlations.

${ }^{\mathrm{c}}$ Mean \pm Standard deviation.

\subsection{Structural Equation Modeling (SEM)}

SEM was used to assess the structure model for the potential factors for the proposed 10 hypotheses. All the standardized path coefficients were shown together with $\mathrm{t}$-values and results for each hypothesis (see Table 3). The total fit of the proposed model was generally confirmed as acceptable $\left(\chi^{2}=282.918 ; \mathrm{df}=142 ; \chi^{2} / \mathrm{df}=1.992, \mathrm{GFI}=0.916\right.$; $\mathrm{NFI}=0.928 ; \mathrm{CFI}=0.963 ; \mathrm{RMSEA}=0.054 ; \mathrm{RMR}=0.047)$. Hypothesis 1 was supported . Perceived usefulness had a significant effect on behavioral intention $(\beta=0.616 ; t=6.788$; $p<0.001)$. Perceived ease of use had no significant effect on behavioral intention $(\beta=0.002$; $t=0.021 ; p>0.05)$. So, Hypothesis 2 was rejected. Hypothesis 3 was supported as a positive relationship was found between perceived usefulness and perceived ease of use ( $\beta=0.429$; $t=6.936 ; p<0.001)$. Trust positively affected perceived usefulness, so Hypothesis 4 was also supported $(\beta=0.521 ; t=8.429 ; p<0.001)$.

Table 3. Structural parameter estimate.

\begin{tabular}{cccc}
\hline $\begin{array}{c}\text { Hypothesized Path } \\
\text { (Stated as Alternative Hypothesis) }\end{array}$ & $\begin{array}{c}\text { Standardized } \\
\text { Path Coefficients }\end{array}$ & $\boldsymbol{t}$-Value & Results \\
\hline H1: PU $\rightarrow$ BI & 0.616 & $6.788^{* * *}$ & Supported \\
H2: PEOU $\rightarrow$ BI & 0.002 & 0.021 & Rejected \\
H3: PEOU $\rightarrow$ PU & 0.429 & $6.936^{* * *}$ & Supported \\
H4: TR $\rightarrow$ PU & 0.521 & $8.429^{* * *}$ & Supported \\
H5: TR $\rightarrow$ PE & 0.506 & $8.251^{* * *}$ & Supported \\
H6: TR $\rightarrow$ PR & -0.147 & $-2.447^{*}$ & Supported \\
H7: TR $\rightarrow$ CS & 0.211 & $3.436^{* * *}$ & Supported \\
H8: PR $\rightarrow$ CS & -0.461 & $-6.377^{* * *}$ & Supported \\
H9: PR $\rightarrow$ BI & -0.116 & $-1.994^{*}$ & Supported \\
H10: CS $\rightarrow$ BI & 0.138 & $2.149^{*}$ & Supported \\
\hline
\end{tabular}

Note: $\chi^{2}=282.918, \mathrm{df}=142, \chi^{2} / \mathrm{df}=1.992$, Goodness of Fit Index $(\mathrm{GFI})=0.916$, Normed Fit Index $(\mathrm{NFI})=0.928$, Comparative Fit Index $(\mathrm{CFI})=0.963$, Root Mean Square Error of Approximation (RMSEA) $=0.054$; Root Mean Square Residual $(\mathrm{RMR})=0.047 .{ }^{* * *} p<0.001,{ }^{*} p<0.05$.

Hypothesis 5 saying that trust would positively affect perceived ease of use was supported $(\beta=0.506 ; t=8.251 ; p<0.001)$. Hypothesis 6 was verified, as a negative relationship existed between perceived trust and perceived risk $(\beta=-0.147 ; t=-2.447$; $p<0.05)$. Hypothesis 7 , which said that trust has a significant effect on customer satisfaction, was supported $(\beta=0.211 ; t=3.436 ; p<0.001)$. Hypothesis 8 was also supported. Perceived risk had a negative effect on customer satisfaction $(\beta=-0.461 ; t=-6.377 ; p<0.001)$. Hypothesis 9 was explained as a negative relationship existing between perceived risk and behavioral intention $(\beta=-0.116 ; t=-1.994 ; p<0.05)$. Lastly, Hypothesis 10 was supported, in that customer satisfaction had a positive significant effect on behavioral intention $(\beta=0.138 ; t=2.149 ; p<0.05)$. In turn, the directions of the proposed hypotheses all corresponded, and the results, except for Hypothesis 2, of the proposed nine hypotheses were all adopted. 


\section{Discussion}

The current study explores how well antecedents can predict consumers' revisit intention to robot service restaurants and proposes a new extended TAM model by integrating three critical variables (trust, perceived risk, and satisfaction) with the original technology acceptance constructs to enrich the understanding of the unique character of robot service in business hotel restaurants. There are new findings regarding the critical variables associated with robot service restaurant consumer behavior.

First, it was confirmed that there is a positive influence of PU on intention to revisit robot service restaurants. It indicates that the more consumers perceive service robots as useful, the more they intend to revisit robot restaurants. This finding agrees with the findings in the previous TAM literature [29,47]. Additionally, the present study finds a positive indirect effect of PEOU on revisit intention through PU. That is, consumers perceive that the easier the robot is to use, the more useful it is, which in turn leads to a positive intention to revisit that robot restaurant.

However, this study also confirmed there was no significant direct relationship between PU and behavioral intention to revisit. Furthermore, the indirect relationship between PEOU and technology acceptance behavior through PU was similar to what was found in a prior study, which applied TAM on the acceptance of biometric technology at music festivals (i.e., fingerprinting) [45].

Secondly, these results confirmed trust as a crucial antecedent variable of TAM. It infers that trust is generally important in the acceptance of robot service restaurants. Trust has been regarded as a potentially essential element for technology acceptance, especially, in uncertain environments [61]. Trust can reduce the perceived social complexity, which is being generated by the interaction with service robots [60]; also, trust can relieve the risk of responsibility from the robot's malfunctioning $[19,20]$. Whenever humans face a high-risk and unpredictable situation, trust becomes a more powerful tool. Thus, trust becomes critical in the service robot environment. The total effects of the three critical variables (Hypothesis $4 \sim$ Hypothesis 10) showed the hierarchical importance of each of these variables for predicting revisit intention to a robot restaurant.

The impact of trust on PU $(\beta=0.521)$ showed the strongest effect and the impact of trust on PEOU $(\beta=0.506)$ as the next strongest effect. It is inferred that when consumers trust the service robots at a restaurant, they will perceive robots as more useful and easy to use. The positive impact of trust on PU is based on the logic that trust allows consumers to become susceptible to the guarantee that they will gain the expected useful interaction they desire from the service robot [16,84]. Trust increases PU because trust decreases the required time and effort to use robots by lessening the special attention required to understand and control new technology. This result is precisely consistent with the prior studies by exploring consumers' behavioral intention to use social media for e-transactions and also by showing the impact of trust on the PU for electronic social media transactions [79] and by determining the impact of trust on the PEOU of e-transactions [68].

Third, the findings revealed that increased trust in robot service decreases the perceived risk, which is in line with the previous extended TAM literature [78,79]. It further suggests that the TAM model could also apply to a robotic system to explain the acceptance of robot service restaurants. It provides empirical data that proves that trust is a powerful means for lowering perceived risk by alleviating consumers' perception of the undesirable consequence of possible technical errors and malfunctions. In other words, lack of trust is identified as one of the major obstacles in the acceptance of robot service.

Finally, the increased trust in robot service increases satisfaction toward robot service restaurants, and the increased perceived risk decreases satisfaction toward robot service restaurants, which is in line with the previous extended TAM studies [89]. The present study found that there is a negative impact of perceived risk toward robot service on consumer satisfaction and intention to revisit robot service at business hotel restaurants. As Table 2 describes, respondents' perceived risk toward robots $(\mathrm{M}=3.718, \mathrm{SD}=0.731)$ is slightly higher than trust $(\mathrm{M}=3.330, \mathrm{SD}=0.699)$; therefore, reducing consumer perceived 
risk toward the chef and serving robot should precede any effort to improve trust at service restaurants.

It also shows that consumers' satisfactions toward robot service at business hotel restaurants increases their intention to revisit positively. This finding is consistent with the several marketing studies' supporting the influence of satisfaction on behavioral intention $[67,83,85]$. The finding further validates the extended TAM for trust, risk, and satisfaction, and explains the consumer behavior regarding robot restaurants by explicitly describing their main effects.

\section{Implications of the Research}

The current study provides several theoretical contributions to the general body of knowledge in the technology literature in the hospitality area. Most of the prior research on robots in hospitality has focused on the hotel context, such as concierge or delivery robots. A few research efforts have empirically tested services of restaurant robots: The association between consumer innovation and customer's attitudes toward restaurant robots [100], restaurant managers' perception of robots [12], and a few qualitative studies [21]. Less research has been undertaken on delivery and chef robots at restaurants. This study enhances the service robot literature by investigating the influencing factors for consumers' behavioral intentions to use robot restaurants.

This study successfully extended TAM to restaurant service robots by grounding new critical variables. It is one of the first studies to integrate trust, perceived risk, and satisfaction with TAM and apply it to robot restaurants. The three critical variables of trust, perceived risk, and satisfaction are arranged in the core original PU-PEOU-acceptance model, and thus, it stabilizes and establishes new model development. Following the outbreak of COVID-19, non-face-to-face services are rapidly becoming a major source of competitive advantage in the service industry. Unfortunately, little was known about how consumers accepted service robots at restaurants. Hence, the newly proposed extension of the TAM model contributes positively to the emerging robot service literature in the hospitality field.

The present study also has implications for future research into the consumer behavior of business hotel restaurant visitors. This study raises the issue of consumer restaurant service robot acceptance, which is a relatively understudied area regarding consumer behavior. It emphasizes risk perception as a major barrier for acceptance of restaurant service robots and trust as an enhancer in the same service robot context. Although extensive e-commerce research has experimentally proven the role of trust and risk in purchase intentions for online behaviors [101,102], empirical research evidence that determines the directional causal relationship from trust to perceived risk in the robot restaurant consumer segment is still limited.

In addition, these empirical results offer important practical directions for increasing behavioral intention for operators who have already provided robot service or have plans to adopt it. First, the present study finds a direct effect of PU and an indirect effect of PEOU on revisit intention. Operators and marketers should provide several benefits to increase their consumers' level of PU. For example, time saving through fast transactions or fast cooking time or an easy ordering process based on a user-friendly robot system might be provided as effective future operating strategies.

Second, this study highlights the crucial role of trust in increasing of PU, PEOU, and satisfaction for the reduction of perceived risk. It indicated that trust in a robot system has the potential benefit of success. Thus, restaurant managers should focus on enhancing robot reliability awareness by image marketing through advertisement exposure or promotional materials to demonstrate the robot's technological innovations.

Third, the results showed the negative influence of perceived risk on satisfaction and revisit intention to robot service restaurants. It indicated that consumers perceived risk is high when they have more uncertainty about malfunction, errors, or technical inaccuracies from unfamiliar serving or chef robots. Adoption of a guaranteed and safe robot system 
(hardware and software) should be a priority for hospitality operators. Further, the creation and promotion of an image of errorless and perfect robots is recommended for hospitality marketers. Providing information can reduce risk perception by eliminating uncertainty. Money-back guarantees (i.e., a simple statement such as "in case of malfunction, we will compensate you") can be an effective risk-reducing marketing strategy by lowering the fear that might arise from using a chef and service robot.

\section{Limitations and Future Research}

Small sample sizes for extended TAM model development based on an online survey might be a concern for this study, since it has limitations for generalization. Future research should re-examine a more diverse sample of respondents. Also, the research design used the scenario-based virtual images of a restaurant. The chef robot and serving robot shown in this current study have not yet been widely commercialized; thus, the scenario-based survey method is presently unavoidable. Since the survey was conducted online, the possibility that the respondents feel favorably toward other technology is considered. Also, the artificial restaurant setting limited generalizability. It is recommended that future research should explore respondents who have experienced actual robot service at restaurants, avoiding the use of an online survey.

This current study found a perceived risk, which emphasizes the performance function as a critical driver of behavioral intention. Given the significance of perceived risk, future research should expand perceived risk as a multidimensional concept (time, financial, psychological, social, and so on) in more detail since this current study focused on only the functional facet of the dimension of perceived risk. In addition, this study resulted from a survey of Koreans, and it is suggested that comparative studies between various countries are necessary, as there may be differences in technology development capabilities country by country. Given this consideration of the noticeable differences in technology levels in various countries, a comparative study on consumers' perception of robot service between countries might provide valuable new information for international operators/marketers. Finally, as mentioned above, even though understanding how trust and perceived risk interact in robot service can provide valuable information to operators/marketers, the integration of new extended TAM with social, emotional, and relational elements would be a potential area for future research and broaden the understanding of the key drivers of robot service users and their behavioral intentions.

Author Contributions: Conceptualization, K.H.S.; methodology, K.H.S.; software, K.H.S.; validation, K.H.S.; formal analysis, K.H.S.; investigation, J.H.L.; resources, K.H.S.; writing—original draft preparation, J.H.L.; writing-review and editing, J.H.L.; supervision, J.H.L. All authors have read and agreed to the published version of the manuscript.

Funding: This research received no external funding.

Institutional Review Board Statement: The study was approved by the Institutional Review Board of University of Ulsan (2020R0028).

Informed Consent Statement: Informed consent was obtained from all subjects involved in the study.

Data Availability Statement: Not applicable.

Conflicts of Interest: The authors declare no conflict of interest.

\section{References}

1. Colby, C.L.; Mithas, S.; Parasuraman, A. Service robots: How Ready Are Consumers to Adopt and What Drives Acceptance? In Proceedings of the 2016 Frontiers in Service Conference, Bergen, Norway, 23-26 June 2016.

2. Wirtz, J.; Patterson, P.G.; Kunz, W.H.; Gruber, T.; Lu, V.N.; Paluch, S.; Martins, A. Brave new world: Service robots in the frontline. J. Serv. Manag. 2018, 29, 907-931. [CrossRef]

3. The Robot Report. Service Robots for Personal and Private Use. 2020. Available online: https://www.therobotreport.com/map/ service-robots-for-personal-and-private-use/ (accessed on 23 July 2020). 
4. Gupta, R. The Hospitable AI: Robotics and Automation in the Hotel Space: 4hoteliers. 2018. Available online: www.4hoteliers. com/features/article/10995 (accessed on 16 June 2018).

5. Baiju, N.T. 7 Hotel Brands that Lead the Hospitality Sector Using Robots. 2019. Available online: https:/ / roboticsbiz.com/7hotel-brands-that-lead-the-hospitality-sector-using-robots / (accessed on 25 February 2021).

6. Holley, P. The Boston restaurant where robots have replaced the chefs. The Washington Post, 17 May 2018.

7. Wan, L.C.; Chan, E.K.; Luo, X. ROBOTS COME to RESCUE: How to reduce perceived risk of infectious disease in Covid19-stricken consumers? Ann. Tour. Res. 2020, 103069. [CrossRef] [PubMed]

8. Qiu, H.; Li, M.; Shu, B.; Bai, B. Enhancing hospitality experience with service robots: The mediating role of rapport building. J. Hosp. Mark. Manag. 2020, 29, 247-268. [CrossRef]

9. Ivanov, S.H.; Webster, C. Adoption of Robots, Artificial Intelligence and Service Automation by Travel, Tourism and Hospitality Companies-A Cost-Benefit Analysis. 2017. Available online: https://ssrn.com/abstract=3007577 (accessed on 10 November 2020).

10. Pan, Y.; Okada, H.; Uchiyama, T.; Suzuki, K. On the Reaction to Robot's Speech in a Hotel Public Space. Int. J. Soc. Robot. 2015, 7, 911-920. [CrossRef]

11. Ivanov, S.; Webster, C.; Garenko, A. Young Russian adults' attitudes towards the potential use of robots in hotels. Technol. Soc. 2018, 55, 24-32. [CrossRef]

12. Lee, W.H.; Lin, C.W.; Shih, K.H. A technology acceptance model for the perception of restaurant service robots for trust, interactivity, and output quality. Int. J. Mob. Commun. 2018, 16, 361. [CrossRef]

13. Ozturk, A.B. Customer acceptance of cashless payment systems in the hospitality industry. Int. J. Contemp. Hosp. Manag. 2016, 28, 801-817. [CrossRef]

14. Park, K.; Park, N.; Heo, W. Factors Influencing Intranet Acceptance in Restaurant Industry: Use of Technology Acceptance Model. Int. Bus. Res. 2018, 11, 1-10. [CrossRef]

15. Benbasat, I.; Wang, W. Trust in and adoption of online recommendation agents. J. Assoc. Inf. Syst. 2005, 6, 4. [CrossRef]

16. Chircu, A.M.; Davis, G.B.; Kauffman, R.J. Trust, expertise and ecommerce intermediary adoption. In Proceedings of the Sixth Americas Conference on Information Systems, Long Beach, CA, USA, 10-13 August 2000; DeGross, J., Ed.; ACM: New York, NY, USA, 2000; pp. 710-716.

17. Pavlou, P.A. Consumer Acceptance of Electronic Commerce: Integrating Trust and Risk with the Technology Acceptance Model. Int. J. Electron. Commer. 2003, 7, 101-134. [CrossRef]

18. Kolesar, M.B.; Galbraith, R.W. A services-marketing perspective on e-retailing: Implications for e-retailers and directions for further research. Internet Res. 2000, 10, 424-438. [CrossRef]

19. Tussyadiah, I.P.; Zach, F.J.; Wangc, J. Do travelers trust intelligent service robots? Ann. Tour. Res. 2020, 81, 102886. [CrossRef]

20. Yagoda, R.E.; Gillan, D.J. You Want Me to Trust a ROBOT? The Development of a Human-Robot Interaction Trust Scale. Int. J. Soc. Robot. 2012, 4, 235-248. [CrossRef]

21. Zemke, D.M.V.; Tang, J.; Raab, C.; Kim, J. How to Build a Better Robot. For Quick-Service Restaurants. J. Hosp. Tour. Res. 2020, 44, 1235-1269. [CrossRef]

22. Hong, J.-W.; Williams, D. Racism, responsibility and autonomy in HCI: Testing perceptions of an AI agent. Comput. Hum. Behav. 2019, 100, 79-84. [CrossRef]

23. Steinbauer, G.A. A survey about faults of robots used in robocup. In Robot Soccer World Cup; Springer: Berlin/Heidelberg, Germany, 2013; pp. 344-355.

24. Han, H.; Jeong, C. Multi-dimensions of patrons' emotional experiences in upscale restaurants and their role in loyalty formation: Emotion scale improvement. Int. J. Hosp. Manag. 2013, 32, 59-70. [CrossRef]

25. Jin, N.P.; Lee, S.; Gopalan, R. How Do Individual Personality Traits (D) Influence Perceived Satisfaction with Service for College Students (C) in a Casual Restaurant Setting (I)?: The CID Framework. J. Hosp. Mark. Manag. 2012, 21, 591-616. [CrossRef]

26. Jin, N.; Line, N.D.; Merkebu, J. The Impact of Brand Prestige on Trust, Perceived Risk, Satisfaction, and Loyalty in Upscale Restaurants. J. Hosp. Mark. Manag. 2015, 25, 523-546. [CrossRef]

27. Kim, S.; Kim, J.; Badu-Baiden, F.; Giroux, M.; Choi, Y. Preference for robot service or human service in hotels? Impacts of the COVID-19 pandemic. Int. J. Hosp. Manag. 2021, 93, 102795. [CrossRef]

28. Lee, Y.; Lee, S.; Kim, D.-Y. Exploring hotel guests' perceptions of using robot assistants. Tour. Manag. Perspect. $2021,37,100781$. [CrossRef]

29. Choi, Y.; Choi, M.; Oh, M.; Kim, S. Service robots in hotels: Understanding the service quality perceptions of human-robot interaction. J. Hosp. Mark. Manag. 2020, 29, 613-635. [CrossRef]

30. Fuentes-Moraleda, L.; Díaz-Pérez, P.; Orea-Giner, A.; Muñoz-Mazón, A.; Villacé-Molinero, T. Interaction between hotel service robots and humans: A hotel-specific Service Robot Acceptance Model (sRAM). Tour. Manag. Perspect. 2020, 36, 100751. [CrossRef]

31. Fusté-Forné, F.; Jamal, T. Co-Creating New Directions for Service Robots in Hospitality and Tourism. Tour. Hosp. 2021, 2, 43-61. [CrossRef]

32. Lin, H.; Chi, O.H.; Gursoy, D. Antecedents of customers' acceptance of artificially intelligent robotic device use in hospitality services. J. Hosp. Mark. Manag. 2019, 29, 530-549. [CrossRef]

33. Leo, X.; Huh, Y.E. Who gets the blame for service failures? Attribution of responsibility toward robot versus human service providers and service firms. Comput. Hum. Behav. 2020, 113, 106520. [CrossRef] 
34. Ho, T.H.; Tojib, D.; Tsarenko, Y. Human staff vs. service robot vs. fellow customer: Does it matter who helps your customer following a service failure incident? Int. J. Hosp. Manag. 2020, 87, 102501. [CrossRef]

35. Nam, K.; Dutt, C.S.; Chathoth, P.; Daghfous, A.; Khan, M.S. The adoption of artificial intelligence and robotics in the hotel industry: Prospects and challenges. Electron. Mark. 2020, 1-22. [CrossRef]

36. Park, S. Multifaceted trust in tourism service robots. Ann. Tour. Res. 2020, 81, 102888. [CrossRef]

37. Samala, N.; Katkam, B.S.; Bellamkonda, R.S.; Rodriguez, R.V. Impact of AI and robotics in the tourism sector: A critical insight. J. Tour. Futur. 2020. [CrossRef]

38. Zhu, D.H.; Chang, Y.P. Robot with humanoid hands cooks food better? Int. J. Contemp. Hosp. Manag. 2020, 32, 1367-1383. [CrossRef]

39. Davis, F.D. A Technology Acceptance Model for Empirically Testing New End-User Information Systems: Theory and Results. Ph.D. Thesis, Massachusetts Institute of Technology, Cambridge, MA, USA, 1986.

40. Davis, F.D. Perceived usefulness, perceived ease of use, and user acceptance of information technology. MIS Q. 1989, 13, 319-340. [CrossRef]

41. Kamal, S.A.; Shafiq, M.; Kakria, P. Investigating acceptance of telemedicine services through an extended technology ac-ceptance model (TAM). Technol. Soc. 2020, 60, 101212. [CrossRef]

42. Kim, T.G.; Lee, J.H.; Law, R. An empirical examination of the acceptance behaviour of hotel front office systems: An extended technology acceptance model. Tour. Manag. 2008, 29, 500-513. [CrossRef]

43. Lew, S.; Tan, G.W.-H.; Loh, X.-M.; Hew, J.-J.; Ooi, K.-B. The disruptive mobile wallet in the hospitality industry: An extended mobile technology acceptance model. Technol. Soc. 2020, 63, 101430. [CrossRef]

44. Ajzen, I.; Fishbein, M. Understanding Attitudes and Predicting Social Behavior; Prentice-Hall: Eaglewood Cliffs, NJ, USA, 1980.

45. Norfolk, L.; O’Regan, M. Biometric technologies at music festivals: An extended technology acceptance model. J. Conv. Event Tour. 2021, 22, 36-60. [CrossRef]

46. Marangunić, N.; Granić, A. Technology acceptance model: A literature review from 1986 to 2013. Univers. Access Inf. Soc. 2015, 14, 81-95. [CrossRef]

47. Venkatesh, V.; Davis, F.D. A model of the antecedents of perceived ease of use: Development and test. Decis. Sci. 1996, 27, 451-481. [CrossRef]

48. Hong, W.; Thong, J.Y.; Wong, W.-M.; Tam, K.-Y. Determinants of User Acceptance of Digital Libraries: An Empirical Examination of Individual Differences and System Characteristics. J. Manag. Inf. Syst. 2002, 18, 97-124. [CrossRef]

49. Amoako-Gyampah, K.; Salam, A. An extension of the technology acceptance model in an ERP implementation environment. Inf. Manag. 2004, 41, 731-745. [CrossRef]

50. Liébana-Cabanillas, F.; Alonso-Dos-Santos, M.; Soto-Fuentes, Y.; Valderrama-Palma, V.A. Unobserved heterogeneity and the importance of customer loyalty in mobile banking. Technol. Anal. Strat. Manag. 2016, 29, 1015-1032. [CrossRef]

51. Tan, G.W.-H.; Lee, V.H.; Lin, B.; Ooi, K.-B. Mobile applications in tourism: The future of the tourism industry? Ind. Manag. Data Syst. 2017, 117, 560-581. [CrossRef]

52. Assaker, G. Age and gender differences in online travel reviews and user-generated-content (UGC) adoption: Extending the technology acceptance model (TAM) with credibility theory. J. Hosp. Mark. Manag. 2020, 29, 428-449. [CrossRef]

53. Kaushik, A.K.; Agrawal, A.K.; Rahman, Z. Tourist behaviour towards self-service hotel technology adoption: Trust and subjective norm as key antecedents. Tour. Manag. Perspect. 2015, 16, 278-289. [CrossRef]

54. Kim, J.S. An extended technology acceptance model in behavioral intention toward hotel tablet apps with moderating effects of gender and age. Int. J. Contemp. Hosp. Manag. 2016, 28, 1535-1553. [CrossRef]

55. Camilleri, M.A.; Falzon, L. Understanding motivations to use online streaming services: Integrating the technology acceptance model (TAM) and the uses and gratifications theory (UGT). Span. J. Mark. ESIC 2020. [CrossRef]

56. King, W.R.; He, J. A meta-analysis of the technology acceptance model. Inf. Manag. 2006, 43, 740-755. [CrossRef]

57. Mun, Y.Y.; Hwang, Y. Predicting the use of web-based information systems: Self-efficacy, enjoyment, learning goal orientation, and the technology acceptance model. Int. J. Hum. Comput. Stud. 2003, 59, 431-449.

58. Nadlifatin, R.; Miraja, B.; Persada, S.; Belgiawan, P.; Redi, A.A.N.; Lin, S.C. The measurement of University students' intention to use blended learning system through technology acceptance model (TAM) and theory of planned behavior (TPB) at de-veloped and developing regions: Lessons learned from Taiwan and Indonesia. Int. J. Emerg. Technol. Learn. 2020, 15, 219-230. [CrossRef]

59. Wang, Y.; Wang, S.; Wang, J.; Wei, J.; Wang, C. An empirical study of consumers' intention to use ride-sharing services: Using an extended technology acceptance model. Transportation 2020, 47, 397-415. [CrossRef]

60. Luhmann, N. Trust and Power; John Wiley and Sons: Chichester, UK, 1979.

61. Gefen, D.; Straub, D.W. Managing user trust in B2C e-services. E Serv. J. 2003, 2, 7-24. [CrossRef]

62. Keen, P.G.W. Electronic Commerce Relationships: Trust by Design; Prentice Hall: Englewood Cliffs, NJ, USA, 1999.

63. Pan, F.C. Practical application of importance-performance analysis in determining critical job satisfaction factors of a tourist hotel. Tour. Manag. 2015, 46, 84-91. [CrossRef]

64. Thrun, S. Toward a framework for human-robot interaction. Hum. Comput. Interact. 2004, 19, 9-24.

65. Alalwan, A.A.; Baabdullah, A.M.; Rana, N.P.; Tamilmani, K.; Dwivedi, Y.K. Examining adoption of mobile internet in Saudi Arabia: Extending TAM with perceived enjoyment, innovativeness and trust. Technol. Soc. 2018, 55, 100-110. [CrossRef] 
66. Söllner, M.; Hoffmann, A.; Leimeister, J.M. Why different trust relationships matter for information systems users. Eur. J. Inf. Syst. 2016, 25, 274-287. [CrossRef]

67. Faqih, K.M.S. Exploring the influence of perceived risk and internet self-efficacy on consumer online shopping intentions: Perspective of technology acceptance model. Int. Manag. Rev. 2013, 9, 67-78.

68. Al-Gahtani, S.S. Modeling the electronic transactions acceptance using an extended technology acceptance model. Appl. Comput. Informatics 2011, 9, 47-77. [CrossRef]

69. Wu, C.H.-J.; Liao, H.-C.; Hung, K.-P.; Ho, Y.-H. Service guarantees in the hotel industry: Their effects on consumer risk and service quality perceptions. Int. J. Hosp. Manag. 2012, 31, 757-763. [CrossRef]

70. Sohn, H.-K.; Lee, T.J.; Yoon, Y.-S. Relationship between Perceived Risk, Evaluation, Satisfaction, and Behavioral Intention: A Case of Local-Festival Visitors. J. Travel Tour. Mark. 2016, 33, 28-45. [CrossRef]

71. Featherman, T.; Pavlou, S. Predicting E-Services Adoption. J. Online Secur. 2002, 3, 83-107.

72. Horst, M.; Kuttschreuter, M.; Gutteling, J.M. Perceived usefulness, personal experiences, risk perception and trust as determinants of adoption of e-government services in The Netherlands. Comput. Hum. Behav. 2007, 23, 1838-1852. [CrossRef]

73. Schiffman, L.G.; Kanuk, L.L. Consumer Behavior, 4th ed.; Prentice-Hall: London, UK, 1991.

74. Morosan, C. Theoretical and empirical considerations of guests' perceptions of biometric systems in hotels: Extending the technology acceptance model. J. Hosp. Tour. Res. 2012, 36, 52-84. [CrossRef]

75. Ganesan, S. Determinants of long-term orientation in buyer-seller relationships. J. Mark. 1994, 58, 1-19. [CrossRef]

76. McKnight, D.H.; Choudhury, V.; Kacmar, C. Developing and Validating Trust Measures for e-Commerce: An Integrative Typology. Inf. Syst. Res. 2002, 13, 334-359. [CrossRef]

77. Slade, E.L.; Dwivedi, Y.K.; Piercy, N.C.; Williams, M.D. Modeling Consumers' Adoption Intentions of Remote Mobile Payments in the United Kingdom: Extending UTAUT with Innovativeness, Risk, and Trust. Psychol. Mark. 2015, 32, 860-873. [CrossRef]

78. Baki, R. Analysis of Factors Affecting Customer Trust in Online Hotel Booking Website Usage. Eur. J. Tour. Hosp. Recreat. 2020, 10, 106-117. [CrossRef]

79. Hansen, J.M.; Saridakis, G.; Benson, V. Risk, trust, and the interaction of perceived ease of use and behavioral control in predicting consumers' use of social media for transactions. Comput. Hum. Behav. 2018, 80, 197-206. [CrossRef]

80. Udo, G.J.; Bagchi, K.K.; Kirs, P.J. An assessment of customers' e-service quality perception, satisfaction and intention. Int. J. Inf. Manag. 2010, 30, 481-492. [CrossRef]

81. Liebermann, Y.; Stashevsky, S. Perceived risks as barriers to Internet and e-commerce usage. Qual. Mark. Res. Int. J. 2002, 5, 291-300. [CrossRef]

82. Ring, P.S.; Van de Ven, A.H. Developmental processes of cooperative interorganizational relationships. Acad. Manag. Rev. 1994, 19, 90-118. [CrossRef]

83. Zhang, X.; Prybutok, V. A Consumer Perspective of E-Service Quality. IEEE Trans. Eng. Manag. 2005, 52, 461-477. [CrossRef]

84. Pavlou, P.A. Integrating trust in electronic commerce with the technology acceptance model: Model development and validation. In Proceedings of the Seventh Americas Conference in Information Systems AMCIS, Boston, MA, USA, 3-5 August 2001; pp. 816-822.

85. Tran, V.D. The Relationship among Product Risk, Perceived Satisfaction and Purchase Intentions for Online Shopping. J. Asian Financ. Econ. Bus. 2020, 7, 221-231. [CrossRef]

86. Yeung, R.; Yee, W.; Morris, J. The effects of risk-reducing strategies on consumer perceived risk and on purchase likelihood. Br. Food J. 2010, 112, 306-322. [CrossRef]

87. Lee, J.H.; Mustapha, A.; Hwang, J. Enhancing ethnic restaurant visits and reducing risk perception. J. Hosp. Tour. Insights 2019, 2, 341-357. [CrossRef]

88. Hofstede, G. Motivation, leadership, and organization: Do American theories apply abroad? Organ. Dyn. 1980, 9, 42-63. [CrossRef]

89. Kim, D.J.; Ferrin, D.L.; Rao, H.R. Trust and Satisfaction, Two Stepping Stones for Successful E-Commerce Relationships: A Longitudinal Exploration. Inf. Syst. Res. 2009, 20, 237-257. [CrossRef]

90. Broadbent, E.; Kuo, I.H.; Lee, Y.I.; Rabindran, J.; Kerse, N.; Stafford, R.; Macdonald, B.A. Attitudes and Reactions to a Healthcare Robot. Telemed. e-Health 2010, 16, 608-613. [CrossRef] [PubMed]

91. Palau-Saumell, R.; Forgas-Coll, S.; Sánchez-García, J.; Robres, E. User Acceptance of Mobile Apps for Restaurants: An Expanded and Extended UTAUT-2. Sustainability 2019, 11, 1210. [CrossRef]

92. Herrero, Á.; Martín, H.S.; Salmones, M.D.M.G.-D.L. Explaining the adoption of social networks sites for sharing user-generated content: A revision of the UTAUT2. Comput. Hum. Behav. 2017, 71, 209-217. [CrossRef]

93. Venkatesh, V.; Thong, J.Y.L.; Xu, X. Consumer Acceptance and Use of Information Technology: Extending the Unified Theory of Acceptance and Use of Technology. MIS Q. 2012, 36, 157-178. [CrossRef]

94. Ejdys, J. Trust in Technology in Case of Humanoids Used for the Care for the Senior Persons. Multidiscip. Asp. Prod. Eng. 2018, 1, 875-881. [CrossRef]

95. Mutahar, A.M.; Daud, N.M.; Ramayah, T.; Ramayah, O.; Aldholay, A.H. The effect of awareness and perceived risk on the technology acceptance model (TAM): Mobile banking in Yemen. Int. J. Serv. Stand. 2018, 12, 180-204. [CrossRef]

96. Kim, M.; Qu, H. Travelers' behavioral intention toward hotel self-service kiosks usage. Int. J. Contemp. Hosp. Manag. 2014, 26, 225-245. [CrossRef] 
97. Jang, H.-W.; Lee, S.-B. Serving Robots: Management and Applications for Restaurant Business Sustainability. Sustainability 2020, 12, 3998. [CrossRef]

98. Fornell, C.; Larcker, D.F. Evaluating structural equation models with unobservable variables and measurement error. J. Mark. Res. 1981, 18, 39-50. [CrossRef]

99. Bagozzi, R.P.; Yi, Y. On the evaluation of structural equation models. J. Acad. Mark. Sci. 1988, 16, 74-94. [CrossRef]

100. Cha, S.S. Customers' intention to use robot-serviced restaurants in Korea: Relationship of coolness and MCI factors. Int. J. Contemp. Hosp. Manag. 2020, 32, 2947-2968. [CrossRef]

101. Van der Heijden, H.; Verhagen, T.; Creemers, M. Understanding online purchase intentions: Contributions from technology and trust perspectives. Eur. J. Inf. Syst. 2003, 12, 41-48. [CrossRef]

102. Tong, X. A cross-national investigation of an extended technology acceptance model in the online shopping context. Int. J. Retail. Distrib. Manag. 2010, 38, 742-759. [CrossRef] 